\title{
Recent advances in neonatology
}

\section{Foreword}

Although this article is published in the Fetal and Neonatal Edition, it was originally commissioned to be of interest to general paediatricians who are not specialists in neonatology, but who are responsible for the provision of much of the UK's neonatal care.

\section{Introduction}

Neonatal medicine continues to make rapid progress. Babies born at 26 weeks of gestation now have a better than evens chance of survival, a remarkable improvement compared to even a decade ago. The combination of antenatal steroids and postnatal surfactant has significantly reduced mortality and the risk of intracranial haemorrhage. Artificial ventilators have become more and more sophisticated and the role of high frequency oscillation (HFOV) as rescue treatment is now established. Infections still contribute to many premature labours, and although the results of the ORACLE trial are still awaited, intrapartum antibiotic prophylaxis against neonatal group B streptococcal infection is gaining widespread acceptance. For term infants with persistent pulmonary hypertension (PPHN), nitric oxide (NO) has made a rapid leap from the laboratory to the cotside and has already proved to be effective treatment.

This review aims to provide a brief update of the most important recent changes in neonatal medicine.

\section{Surfactant treatment}

Exogenous surfactant has now been in use for nearly a decade. Surfactant reduces neonatal mortality from respiratory distress syndrome (RDS) by about $40 \%$ and reduces complications like air leaks by up to $60 \% .^{1-3}$ The combination of postnatal surfactant with antenatal steroids is more effective than either treatment alone. ${ }^{4}$ Surfactant treatment has no effect against chronic lung disease (CLD), gross maternal haemorrhage-intraventricular haemorrhage (GMH-IVH), and patent ductus arteriosus (PDA). ${ }^{5}$ The controversies that remain are not to do with surfactant use in typical RDS, but are about which product is superior; whether there is a lower gestation or weight limit at which surfactant should be withheld; and the choice between rescue and prophylactic treatment. Indications for surfactant use in conditions other than RDS, such as meconium aspiration syndrome, are beginning to emerge. ${ }^{6}$

PROPHYLAXIS $V S$ RESCUE TREATMENT

Now that it is accepted surfactant improves the outlook for neonatal RDS, the critical issue is timing. The simple answer seems to be that treatment should be given as early as possible, once a preterm baby is intubated, and ideally within the first few breaths of life. Seven randomised controlled trials have compared surfactant treatment at birth (prophylaxis) with treatment a few hours later (rescue). Prophylaxis was more effective than rescue treatment. ${ }^{7}$ The odds ratios (95\% confidence intervals) in favour of prophylaxis were $0.59(0.46$ to 0.76$)$ for neonatal mortality, $0.62(0.42$ to 0.89$)$ for pneumothoraces, and 0.54 (0.36 to 0.82$)$ for pulmonary interstitial emphysema.
Current recommendations are to give prophylactic surfactant to all babies who are intubated for resuscitation at less than 32 weeks of gestation.

Later administration of surfactant will be beneficial in larger infants who develop RDS, and in some trials the first treatment has been as late as 72 hours after birth. There is little evidence to support surfactant administration beyond this time. Multiple doses are better than a single dose for infants who remain ventilated. ${ }^{8}$

Where infants are to be transferred, surfactant should still be administered as early as possible and before transfer. However, it is important that those using this treatment are familiar with the rapid changes in ventilator requirements which often follow the administration of natural surfactants. There is no evidence that harm has been done by giving either natural or synthetic prophylactic surfactant. There is a practical problem with one or two of the surfactants as they involve delivering large volumes into the trachea, and a divided dose may be necessary. The answer would be to use a method or a product where this is not an issue, but the ideal solution to this problem has yet to be found.

NATURAL $v S$ SYNTHETIC SURFACTANT

Four surfactants are licensed in the UK for treating babies. They are animal derived and synthetic surfactants. The animal derived surfactants comprise Curosurf, which is an extract of pig lung mince and given in a volume of 1.25 to $2.5 \mathrm{ml} / \mathrm{kg}$, and Survanta, an extract of cow lung mince with three added lipids, given as a dose of $4 \mathrm{ml} / \mathrm{kg}$. These surfactants contain the apoproteins SP-B and SP-C, and these are thought to enhance their properties. The synthetic surfactants comprise Exosurf, a mixture of the key phospholipid DPPC, hexadecanol, and tyloxapol, given in a volume of $5 \mathrm{ml} / \mathrm{kg}$, and ALEC, a mixture of DPPC and phosphatidylglycerol, given as a dose of $1.2 \mathrm{ml}$, regardless of size.

Fifteen studies have compared different surfactants, seven of which were of suitable quality for meta-analysis. ${ }^{9}$ Six of these trials compared Survanta and Exosurf; the other trial compared Infasurf and Exosurf. The meta-analyses support a significant reduction in the risk of pneumothorax (0.69 CI 0.57 to 0.85 ), and showed a non-significant trend towards reduced mortality. Soll's conclusion was that: "on clinical grounds, natural surfactant extracts were the more desirable choice." The onset of action is more rapid with animal derived surfactants than with artificial surfactants. This means that the babies treated with these surfactants need to be carefully monitored and their ventilator settings adjusted appropriately. Concern has been expressed because rapid effects lead to temporary changes in cerebral blood flow velocity and EEG recordings. There is currently no evidence to suggest that this more rapid onset of action has any deleterious effects.

UPPER AND LOWER GESTATIONAL AGE LIMITS FOR SURFACTANT TREATMENT

Although the data are limited due to small numbers in trials, the data that can be extracted show benefit for the smallest of babies. ${ }^{1011}$ Gestational or weight limits for 
either giving or withholding surfactant are not helpful, and may deprive babies who could benefit from surfactant use.

INDICATIONS FOR SURFACTANT USE IN OTHER CONDITIONS There have been several small trials on the use of surfactant outside the classic indication of RDS, such as sepsis, pulmonary haemorrhage, or meconium aspiration syndrome. ${ }^{12}$ All of these show some benefits. Most convincing to date is the trial using beractant (Survanta) in ventilated cases of meconium aspiration syndrome. Using a higher than normal dose of this surfactant $(150 \mathrm{mg}$ or 6 $\mathrm{ml} / \mathrm{kg}$ ), the trial showed improving oxygenation, and reduced air leaks, severity of pulmonary morbidity, and shorter inpatient stay among term infants. ${ }^{6}$

\section{Inhaled nitric oxide}

The discovery that endothelium derived relaxing factor (EDRF) was in fact a gas, NO, has revolutionised thinking about several diseases. The NO pathway seems to have a crucial role in the vasoactivity of the pulmonary vascular bed. ${ }^{13}$ PPHN may be in part due to a deficiency of or resistance to $\mathrm{NO},{ }^{14}$ and the endothelial cellular defects may represent a final common pathway for the diverse causes for PPHN.

Once suitable delivery systems were developed, inhaled $\mathrm{NO}$ was first tested in neonatal pilot studies and then full scale randomised controlled trials. The results of a large trial on the use of inhaled NO in full term infants with hypoxic respiratory failure were published in $1997 . .^{15}$ The results showed that babies who received $\mathrm{NO}$ were less likely to require extra corporeal membrane oxygen (ECMO). Most of these babies were pre-treated with surfactant. The dose of NO used was 20 to $80 \mathrm{ppm}$; infants who responded usually did so at the lower dose, although a few responded only to the higher dose. The results have been confirmed in further trials, which again showed no difference between doses of 5, 20, or $80 \mathrm{ppm} .{ }^{16}{ }^{17}$ Methaemoglobinaemia of greater than $7 \%$ (normally less than $1 \%$ ) was more common in the group who received $80 \mathrm{ppm}$. Theoretical concerns about an increase in bleeding time have not so far translated into clinical complications.

NO needs to be used with caution in clinical treatment. The gas must be carefully diluted down to a concentration of 10-80 ppm in oxygen/air, and the concentration monitored before it can be safely administered to babies. Nitric oxide is oxidised to higher oxides of nitrogen $\left(\mathrm{NO}_{2}\right.$ to $\left.\mathrm{NO}_{\mathrm{x}}\right)$ in the presence of oxygen. Nitrogen dioxide $\left(\mathrm{NO}_{2}\right)$ is a toxic gas that has already been comprehensively studied as a component of car exhaust fumes. Current occupational health guidelines limit exposure of $\mathrm{NO}_{2}$ to $5 \mathrm{ppm}$, and histological changes have been seen in lungs exposed to 25 ppm of $\mathrm{NO}_{2}$. NO must be added to the baby's inspired gases right at the patient manifold of the circuit, to limit contact time between $\mathrm{NO}$ and oxygen, and the concentrations of $\mathrm{NO}_{2}$ to $\mathrm{NO}_{\mathrm{x}}$ must be monitored in the expiratory limb. Waste gas must be scavenged to avoid contaminating the working environment, and ventilators purged after use. Nitrogen dioxide does not accumulate beyond safe levels if equipment is used carefully. Once started, inhaled NO should be cautiously weaned as there may be down regulation, often transient, of endogenous NO synthetase activity. ${ }^{18}$ Nitric oxide is now well established as a treatment for PPHN, a condition for which a multitude of injectable vasodilators had previously been tried without any randomised controlled trial evidence to support improved outcome from any of them.

Treatment with high frequency oscillatory ventilation plus inhaled NO may be more successful than with inhaled NO or HFOV alone in severe PPHN. ${ }^{19}$ This study also suggested that the differences in responses may partly be related to the specific diseases associated with PPHN. These workers concluded that for patients with PPHN, which was complicated by severe lung disease, response rates for HFOV plus inhaled NO were better than HFOV or inhaled NO alone with conventional ventilation. For patients without clinically significant parenchymal disease, both inhaled NO and HFOV plus inhaled NO were more effective than HFOV alone.

Inhaled NO has been used in situations other than classic PPHN. The NINOS group reviewed inhaled NO in congenital diaphragmatic hernias and concluded that it did not reduce the need for ECMO or the incidence of death. ${ }^{20}$ Fifty three infants were enrolled into this trial; in spite of aggressive management, including ventilation, alkalosis, surfactant, inhaled $\mathrm{NO}$ and ECMO, the mortality was almost $50 \%$ in both arms of the trial. The place of inhaled NO in treating premature babies who have pulmonary hypertension as a component of their RDS, also remains uncertain. One four way prospective trial comparing dexamethasone and inhaled NO, concluded that both or neither failed to show any benefit for any group. ${ }^{21}$

\section{Prophylaxis against group B streptococcal infection}

Group B streptococcus is the leading cause of serious neonatal infection. Infants who are infected with it can require prolonged hospital stay, and a third of the survivors sustain permanent sequelae. There is no doubt that selective intrapartum prophylaxis is effective, and this has been confirmed by a meta-analysis which showed a 30-fold reduction in group B streptococcal disease..$^{22}{ }^{23}$ More than a decade has passed since the first clinical trial showed the effectiveness of intrapartum antibiotic prophylaxis, ${ }^{24}$ but still prevention strategies have not been implemented widely or consistently, and the incidence of neonatal group $\mathrm{B}$ streptococcal infection has not declined.

The alternative strategies currently available and the difficult choices they present were recently thoroughly reviewed by Isaacs. ${ }^{25}$ The choice between inactivity (treating only symptomatic babies), universal screening, and treating on the basis of risk factors alone remains. Isaacs concluded that preventive measures may not be justified in terms of cost effectiveness when the incidence was below 0.6 per 1000 , but there are no accurate incidence figures for most of the UK. In the Northern Region the incidence was recently estimated as at least 1 case per 1000 deliveries whereas in Oxford it was 0.5 per $1000 .{ }^{26}$ Confirmed cases of early onset group B streptococcal infection reported to the Public Health Laboratory Service this year suggest an incidence of exactly 0.6 per 1000 , uncomfortably near a level at which screening ought to be considered for the UK population.

\section{Extra corporeal membrane oxygenation}

ECMO involves oxygenating blood outside the body and providing cardiovascular support, using complex machinery resembling that used for cardiopulmonary bypass. ECMO can be used only in babies weighing more than 2 $\mathrm{kg}$, and candidates for this treatment usually have PPHN or meconium aspiration syndrome. ECMO has now been used on over 11000 infants worldwide, with $80 \%$ survival reported. Traditional ECMO uses two large gauge catheters, usually one in the jugular vein and one in the carotid artery. ${ }^{27}$ This form of veno-arterial ECMO involves permanent sacrifice of one carotid artery, and more recently veno-venous ECMO has become more popular. While babies are on ECMO the ventilator is reduced to "rest"settings, allowing the lungs to recover without barotrauma. In general, about two weeks is the maximum time for which babies can safely be sustained on ECMO.

The UK collaborative ECMO trial enrolled 185 infants in two years; 30 of 93 infants allocated ECMO died com- 
pared with 54 of 92 allocated conventional care. ${ }^{28}$ Two thirds of the cases were enrolled in the first 12 months of the trial, in 1993-94. Infants with congenital diaphragmatic hernia are an important subgroup for whom no benefit from ECMO has yet been shown, but small numbers of cases preclude a meta-analysis and some centres claim good results. Only four of the 35 infants with $\mathrm{CDH}$ in the UK trial survived, and all were in the ECMO arm of the trial. Concern about quality of survival remains. Forty five of $62(73 \%)$ babies treated with ECMO in the UK trial seemed to be normal at one year of follow up. The international registry records that $17 \%$ of infants treated this way sustain an intracranial haemorrhage or infarction. ${ }^{29}$ A five year follow up of 103 children treated with ECMO revealed a $17 \%$ prevalence of major disability, with concern about difficult behaviour and academic failure in a higher percentage. ${ }^{30}$ Deafness seems to be a particular risk.

The ECMO trial began just about the time that the first babies were being treated with $\mathrm{NO}$, and the numbers of neonates being offered ECMO each year in the UK is currently declining. There seems little doubt that the facility needs to be available in the UK, at a few specifically designated centres that can maintain levels of expertise because they are caring for enough cases each year. Because of the small number of ECMO centres, the difficulty for the future will be in identifying and referring appropriate cases in time. An oxygenation index of 40 or above predicted $60 \%$ mortality in the ECMO trial, and if this index does not rapidly fall with $\mathrm{NO}$ and/or HFOV, too much time should not be wasted in considering ECMO. Ten of the 30 deaths in the ECMO arm of the UK trial occurred among the 15 infants who were allocated to ECMO, but did not actually receive it.

\section{High frequency oscillation ventilation}

High frequency oscillatory ventilation alternately subjects the lungs to positive and negative pressure at very fast rates, usually about $10 \mathrm{~Hz}$ (10 cycles per second). Special equipment is required to achieve effective ventilation at such high frequencies, and of the three oscillators available in the UK, only the Sensormedics 3100/3100A has been used in randomised controlled trials. The Sensormedics is a dedicated oscillator. The other available oscillators are the Draeger Babylog 8000 and the SLE HV2000 ventilator. Oscillators are powerful tools, and there is no doubt that in "rescue" mode HFOV can save infants with severe RDS who have failed to respond to conventional ventilation and surfactant. ${ }^{31} \mathrm{HFOV}$ is particularly effective in hypercarbia. What is less certain is the role of HFOV as the primary mode of ventilation in RDS in very small babies who have received antenatal steroids and postnatal surfactant. ${ }^{32}$ The Provo trial ${ }^{33}$ randomly allocated 125 babies with RDS at less than 35 weeks of gestation who had received surfactant. Those who were ventilated with HFOV fared better than those ventilated conventionally in the short term, with more survivors without chronic lung disease at 30 days. Although there has been some concern about the high number of babies still ventilated at a month (half the HFOV group and all the conventionally ventilated group), the incidence of ultrasound abnormalities and retinopathy of prematurity was the same. Even this large study only enrolled 21 babies with a birthweight of less than $1 \mathrm{~kg}$. HFOV is not the same as high frequency jet ventilation (HFJV). This involves the delivery of a jet of gas directly into the trachea, and lacks an active expiratory phase. Recent evaluations from the USA suggest an excess of cystic periventricular leucomalacia (PVL) in survivors ventilated this way. The increased risk of PVL is perhaps due to hypocarbia. ${ }^{34}$ A meta-analysis of trials of high fre- quency ventilation revealed a higher incidence of intraventricular haemorrhage and PVL which disappeared if the results of the large $\mathrm{HiFi}$ trial were excluded. ${ }^{36}{ }^{37} \mathrm{HFOV}$ is currently reserved for rescue treatment in most UK neonatal units, although a large MRC sponsored trial of the use of HFOV from birth in infants 26-29 weeks of gestation (the UKOS trial) is actively recruiting.

J M RENNIE

Department of Paediatrics

King's Healthcare NHS Trust

King's College Hospital

London SE5 9RS

S A BOKHARI

Department of Paediatrics

Queen Mary's Hospital

Sidcup

Kent DA14 6LT

1 Morley CJ. Systematic review of prophylactic versus rescue surfactant. Arch Dis Child 1997;77:F70-F4.

2 Soll RF. Update Software. Prophylactic administration of natural surfactant (Cochrane review). 4 edn. Oxford: 1998

3 Soll RF. Update Software. Prophylactic synthetic surfactant in preterm infants (Cochrane Review). 4 Edn. Oxford: 1998.

4 Jobe AH, Mitchell BR, Gunkel JH. Beneficial effects of the combined use of prenatal corticosteroids and postnatal surfactant on preterm infants. $A m \mathcal{F}$ Obstet Gynecol 1993;168:508-13.

5 Soll RF. Appropriate surfactant usage in 1996. Eur $\mathcal{F}$ Pediatrics 1996;155:S8S13.

6 Findlay RD, Taeusch HW, Walther FJ. Surfactant replacement therapy for meconium aspiration syndrome. Pediatrics 1996;97:48-52.

7 Soll RF, Morley CJ.Update Software. 4 Edn. Prophylactic surfactant versus treatment with surfactant (Cochrane Review). Oxford: 1998.

8 Speer CP, Robertson B, Curstedt T, Halliday H, Compagnone D, Gefeller $\mathrm{O}$, Harms K. Randomised European multicentre trial of surfactant $\mathrm{O}$, Harms $\mathrm{K}$. Randomised European multicentre trial of surfactant
replacement therapy for severe neonatal respiratory distress syndrome: replacement therapy for severe neonatal respiratory distress syn
single versus multiple doses of Curosurf. Pediatrics 1992;89:13-20.

9 Soll RF. Update Software. 4 th Edn. Natural surfactant extract vs synthetic surfactant in the treatment of established respiratory distress syndrome (Cochrane review). Oxford: 1998

10 American Exosurf Neonatal Study Group. Controlled trials of a single dose of synthetic surfactant at birth in premature infants weighing 500-699 grams. F Pediatrics 1992;120:S3-S12.

11 Ten Centre Study Group. Ten centre trial of artificial surfactant (artificial lung expanding compound) in very premature infants. $B M \mathcal{F}$ 1987;294:991-6.

12 Sim B. Use of surfactant in pulmonary disorders in full term infants. Curr Op Pediatrics 1996;8:113-7.

13 Abman SH, Chatfield BA, Hall SL, McMurty IF. Role of enotheliumderived relaxing factor during transition of pulmonary circulation at birth. Am ₹ Radiol 1993;259:H1921-H7.

14 Haworth SG. The pathophysiology of persistent pulmonary hypertension of the newborn. Semin Neonatol 1997;2:13-23.

15 Neonatal inhaled nitric oxide study group. Inhaled nitric oxide in full term and nearly full-term infants with hypoxic respiratory failure. $N$ Engl $\mathcal{F}$ Med 997:336:597-604

16 Roberts JD, Fineman JR, Morin FCI, et al. Inhaled nitric oxide and persistent pulmonary hypertension of the newborn. N Engl F Med 1997;336:60510 .

17 Davidson D, Barefield ES, Kattwinkel J, et al. Inhaled nitric oxide for the early treatment of persistent pulmonary hypertension of the term newborn: a randomized, double-masked, placebo-controlled, doseresponse, multicenter study. Pediatrics 1998;101:325-34.

18 Miller OI. Rebound pulmonary hypertension on withdrawal from nitric oxide. Lancet 1995;346:51-2.

19 Kinsella JP, Truog WE, Walsh WF, et al. Randomized, multicenter trial of inhaled nitric oxide and high frequency oscillatory ventilation in severe persistent pulmonary hypertension of the newborn. $\mathcal{f}$ Pediatrics 1997;131:55-62.

20 Neonatal inhaled nitric oxide study group. Inhaled nitric oxide and hypoxic respiratory failure in infants with congenital diaphragmatic hernia. Pediatrics 1997;99:838-45.

21 Subhedar NV, Ryan SW, Shaw NJ. Open randomised controlled trial of inhaled nitric oxide and early dexamethasone in high risk infants. Arch Dis Child 1997;77:F185-F90.

22 Allen UD, Navas L, King S. Effectiveness of intrapartum penicillin prophylaxis in preventing early onset group B streptococcal infection: results of a laxis in preventing early onset group B streptococca
meta-analysis. Can Med Assoc f 1993;149:1659-65.

23 Smaill F. Neilson JP, eds. Update Software. Intrapartum antibiotics for GBS colonisation. Pregnancy and Childbirth Module of the Cochrane database of systematic reviezws. Oxford: 1997:1-6.

24 Boyer KM, Gotoff SP. Prevention of early onset neonatal group B streptococcal disease with selective intrapartum chemoprophylaxis. $N$ Engl F Med 1986;314:1165.

25 Isaacs D. Prevention of early onset group B streptococcal infection: screen, treat or observe? Arch Dis Child 1998;79:F81-F2

26 Moses LM, Heath PT, Wilkinson AR, Jeffery HE, Isaacs D. Early onset group B streptococcal neonatal infection in Oxford 1988-96. Arch Dis Child 1998;79:F148-F9.

27 Field DJ. Clinical management of persistent pulmonary hypertension of the newborn. Semin Neonatol 1997;2:59-68.

28 K Collaborative ECMO Trial Group. UK collaborative randomised trial of neonatal extracorporeal membrane oxygenation. Lancet 1996;348:75-82.

29 Soll RF. Neonatal extracorporeal membrane oxygenation- a bridging technique. Lancet 1996;348:70-1.

30 Glass P, Wagner AE, Papero PH, et al. Neurodevelopmental status at age five years of neonates treated with extracorporeal membrane oxygenation. $\mathcal{F}$ Pediatrics 1995;127:447-56. 
31 Clark RH, Yoder BA, Sell MS. Prospective randomised comparison of high frequency oscillation and conventional ventilation in candidates for extracorporeal membrane oxygenation. F Pediatrics 1994;124:447-54

32 Marlow N. High frequency ventilation and respiratory distress syndrome: do we have an answer? Arch Dis Child 1998;78:F1-F2.

33 Gerstmann DR, Minton SD, Stoddard RA. The Provo multicentre early high frequency oscillatory ventilation trial: improved pulmonary and clinical outcome in respiratory distress syndrome. Pediatrics 1996;98:1044-57.

34 Wiswell TE, Graziani LJ, Kornhauser MS, et al. High-frequency jet ventilation in the early management of respiratory distress syndrome is associated with a greater risk for adverse outcomes. Pediatrics 1996;98:1035-43.
35 Wiswell TE, Graziani LJ, Kornhauser MS, et al. Effects of hypocarbia on the development of cystic periventricular leukomalacia in premature nfants treated with high-frequency jet ventilation. Pediatrics 1996;98:918-24.

36 Clark RH, Dykes FD, Bachman TE, Ashurst JT. Intraventricular hemorrhage and high-frequency ventilation: a meta-analysis of prospective clinical trials. Pediatrics 1996;98:1058-61.

37 The HiFi Study Group. High-frequency oscillatory ventilation compared with conventional mechanical ventilation in the treatment of respiratory failure in preterm infants. $N \mathrm{Engl} \mathrm{F} \mathrm{Med} \mathrm{1989;320:88-93.}$ 